\title{
Q1 Avaliação sustentável de biogás em unidade de produção de suínos e seu reaproveitamento energético
}

Diego Bedin Marin ${ }^{1}$

Alessandro Vieira Veloso ${ }^{2}$

Matheus Campos Mattioli3

Jefferson Francisco Soares ${ }^{4}$

\section{Resumo}

Objetivou-se neste trabalho analisar, em quantidade e em qualidade, o biogás proveniente de uma unidade de produção de suínos, relatando o seu reaproveitamento energético. A quantidade de biogás produzida nos biodigestores foi determinada pela demanda do conjunto motor gerador. No que se refere às análises qualitativas do biogás, utilizou-se do kit portátil para análise da concentração de gases em biogás, que permite as análises de gás sulfídrico $\left(\mathrm{H}_{2} \mathrm{~S}\right)$, amônia $\left(\mathrm{NH}_{3}\right)$, gás carbônico $\left(\mathrm{CO}_{2}\right)$ e metano $\left(\mathrm{CH}_{4}\right)$. Pelos resultados obtidos tem-se que a estimativa da produção diária de biogás foi de $1.178,40 \mathrm{~m}^{3}$. Considerando as concentrações de amônia presentes no biogás, os valores encontrados foram iguais a zero para três das 10 amostragens realizadas; em uma amostragem, o valor obtido foi igual a 15 ppmV (partes por milhão por volume); em seis amostragens, os valores obtidos foram de 175 ppmV. O número de amostragens realizadas também foi 10 para as concentrações de gás sulfídrico e foram encontradas as concentrações de 610 ppmV em nove observações. Por sua vez, em apenas uma das análises, foi encontrada a concentração de 460 ppmV. Em tempos de adequação à legislação ambiental e na busca pela sustentabilidade, o processo de biodigestão anaeróbia pela implementação de biodigestores representa uma opção para o manejo e tratamento da biomassa residual da atividade suinícola, produzindo a geração de impactos positivos no meio rural.

Palavras-chave: Construções. Dejetos de suínos. Energia Renovável. Suinocultura. Sustentabilidade.

\section{Introdução}

Há séculos o homem pratica a agricultura, a qual pode ser sumarizada pela manipulação dos sistemas naturais, modificando a paisagem e estrutura organizacional desses sistemas para fins de produção de plantas e animais. A agricultura vem se intensificando na atualidade devido à demanda, cada vez mais crescente, da população, de alimentos e matéria-prima (GARCIA, 2001; ODUM, 1995).

Assim como toda atividade de produção, a agricultura também é consumidora de energia e, além da energia encontrada livremente na natureza, a agricultura utiliza grande quantidade de energia adicionada pelo homem, principalmente a energia advinda de combustíveis fósseis. Esse modelo

1 Universidade Federal de Lavras, bolsista de mestrado. db.marin@hotmail.com. Av. Doutor Sylvio Menicucci, 1001, Caixa Postal 3037, Lavras (MG), CEP 37200-000.

2 Universidade Federal de Lavras, professor. alessandro.veloso@deg.ufla.br.

3 Universidade Federal de Lavras, bolsista de doutorado. mattioli-cmatheus@hotmail.com.

4 Universidade Federal de Lavras, bolsista de doutorado. mattioli-jefferson_fsoares@live.com. 
de produção associado à demanda cada vez maior da sociedade potencializa a escassez dos recursos naturais, comprometendo a sustentabilidade dos agroecossistemas (SANTOS; SIMON, 2010).

Neste cenário, o consumo de energia, por estar presente em todas atividades produtivas, causa inevitavelmente impacto sobre o meio ambiente. Logo, faz-se necessário melhorar a eficiência na transformação e distribuição, bem como descentralizar a produção de energia para que se obtenha maior sustentabilidade dos sistemas de produção (COSTA; BUENO, 2010).

Assim sendo, é importante considerar a atividade suinícola que, nas últimas décadas, alcançou altos níveis de produção com o crescimento no uso dos sistemas confinados, os quais preveem grande concentração de animais em pequeno espaço, gerando uma grande quantidade de poluente de forma localizada, podendo ocasionar uma degradação ambiental (ORRICO JÚNIOR et al., 2011).

Diante dessa questão ambiental, há diversas tecnologias para o manejo e tratamento dos resíduos, entre elas, o processo de biodigestão anaeróbia, especialmente pela implantação de biodigestores (ESPERANCINI et al., 2007), que podem proporcionar inúmeros benefícios, como a geração de energia renovável, produção de biofertilizante, bem como a mitigação da poluição do ar, solo e água (ANGONESE et al., 2007).

De acordo com Veloso et al. (2012), todo processo de produção gera resíduos e todo resíduo armazena determinada quantidade de energia, desta forma, os sistemas de produção, inclusive a suinocultura, podem transformar resíduos em energia, diminuindo seu custo de produção e, consequentemente, mitigando o seu impacto ambiental.

No presente trabalho, objetivou-se analisar, em quantidade e em qualidade, o biogás proveniente de uma unidade de produção de suínos, relatando o seu reaproveitamento energético.

\section{Material e métodos}

\section{Caracterização da unidade de produção de suínos}

O estudo foi desenvolvido na Granja Niterói (FIGURA 1), que possui sistema de produção de suínos de ciclo completo, localizada no município de Lavras, estado de Minas Gerais (VELOSO, 2014). 
Figura 1. Delimitação do sistema de produção estudado. Observações: $A=$ galpões do setor de reprodução; $B=$ galpões do setor de maternidade; $C=$ galpões do setor de creche; $D=$ galpões do setor de crescimentoterminação; $\mathrm{E}$ = tanque de equalização; $\mathrm{F}=$ caixa difusora de fluxo; $\mathrm{G}=$ biodigestores; $\mathrm{H}=$ lagoa de estabilização; $I$ = conjunto motor gerador de eletricidade; $\mathrm{J}=$ fábrica de ração; $\mathrm{L}$ = caixas de água; $M=$ silos; $\mathrm{N}=$ residência; $\mathrm{O}=$ refeitório e vestiário; $\mathrm{P}=$ composteira.

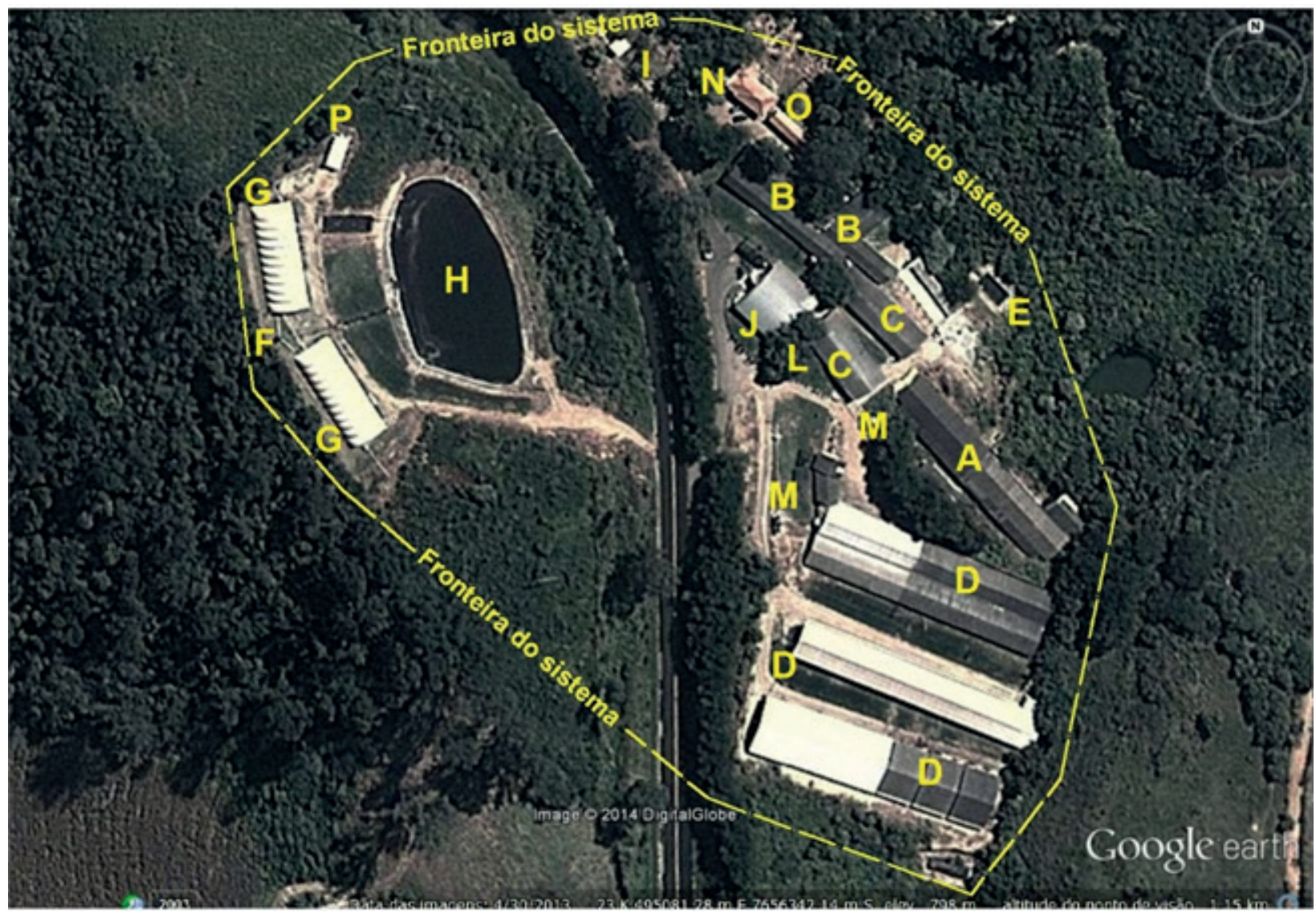

Fonte: Veloso (2014).

As edificações suinícolas ("A", "B", "C" e "D", FIGURA 1) que compõem o sistema de produção totalizam $5.974 \mathrm{~m}^{2}$ de área interna, onde são alojados 5.955 animais, entre os quais estão 411 matrizes e quatro cachaços.

As instalações para o confinamento de suínos ("A", "B", "C" e "D", FIGURA 1) são compostas por 15 galpões construídos, em grande parte, de alvenaria, os quais apresentam pés-direitos de 3,0 m. Essas edificações estão orientadas na direção leste-oeste, possuindo coberturas em telhas de fibrocimento de 6,0 mm de espessura, que estão suportadas por tesouras metálicas, as quais estão apoiadas em pilares de concreto. Visando impedir a entrada da água da chuva, os galpões são dotados de beirais com 0,90 m.

Estas edificações ("A", "B", "C" e "D", FIGURA 1) estão divididas em função da fase de vida e atividade, sendo diferenciadas em galpões para o setor de reprodução (pré-cobrição, cobrição e gestação), setor de maternidade, setor de creche e setor de crescimento-terminação. 
Nos galpões de produção ("A", "B", "C" e “D”, FIGURA 1), são identificados os pisos parcialmente ripados e o piso compacto, cada um com suas peculiaridades no que se refere à coleta e remoção de dejetos.

Os resíduos são manejados na forma líquida e coletados em um fosso, situado na parte inferior das edificações, de onde são escoados, pela ação da gravidade, para um tanque de equalização ("E", FIGURA 1), por meio de tubulações de policloreto de vinila (PVC). A produção diária de biomassa residual é de $54,85 \mathrm{~m}^{3}$.

O sistema de tratamento de resíduos é constituído por um tanque de equalização, dois biodigestores e uma lagoa de estabilização ("E", "G" e "H", FIGURA 1).

O tanque de equalização ("E" FIGURA 1 e FIGURA 2) possui 210,33 m³ de volume, tendo a base menor (fundo) dimensões de $11 \times 6 \mathrm{~m}$, a base maior (borda superior do tanque) dimensões de $15 \times 10 \mathrm{~m}$, com profundidade de $2 \mathrm{~m}$. Essa estrutura dispõe de um conjunto motobomba helicoidal de $25 \mathrm{~m}^{3} \mathrm{~h}^{-1}$ de vazão e $15 \mathrm{cv}$ de potência, que propicia a elevação do efluente até uma caixa difusora de fluxo construída em polietileno ("F", FIGURA 1), que distribui os resíduos para dois biodigestores, localizados em nível mais elevado na propriedade.

Figura 2. Tanque de equalização

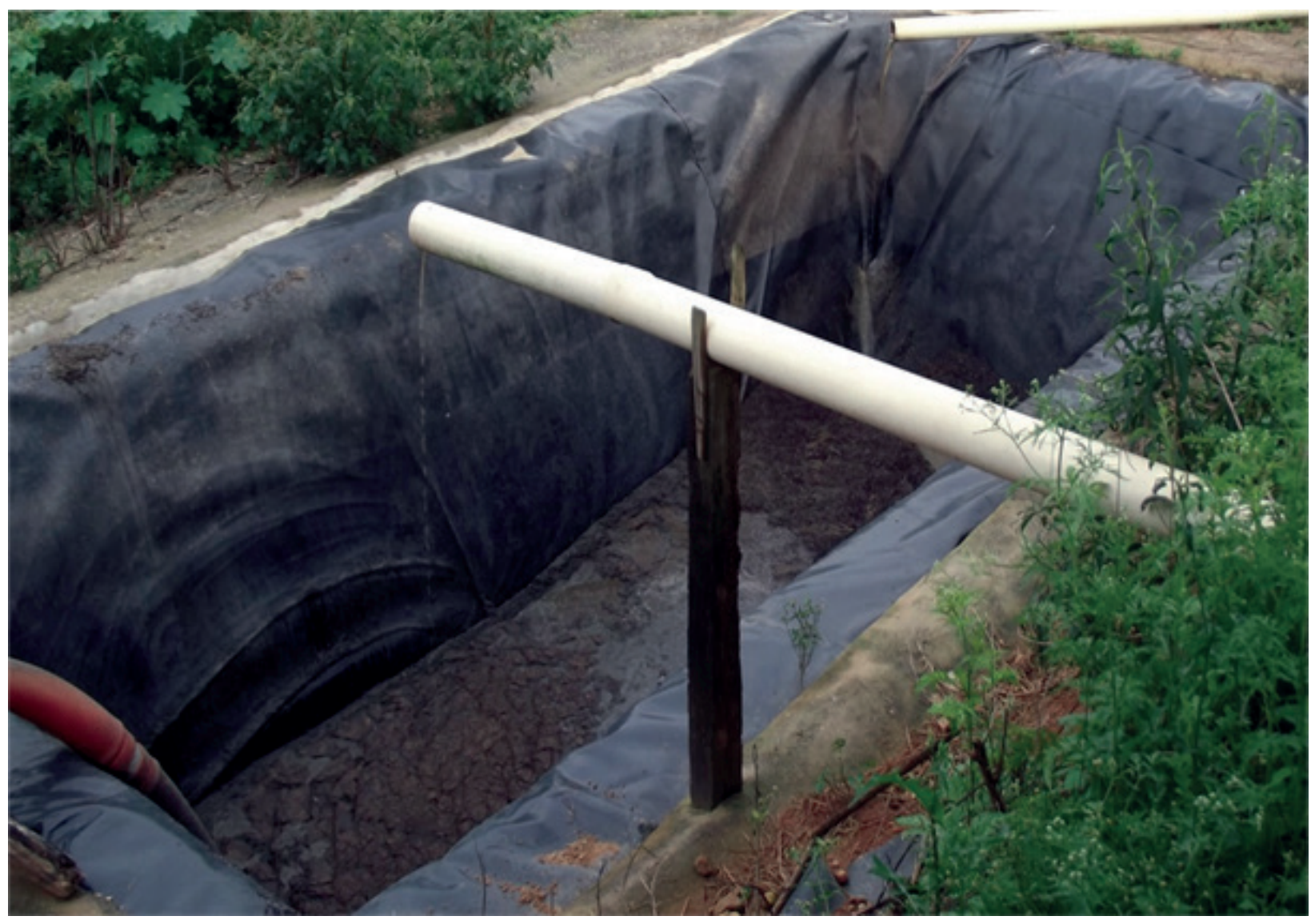

Fonte: Veloso (2014). 
Dois biodigestores modelo canadense ("G", FIGURA 1 e FIGURA 3) realizam o tratamento dos resíduos. A parte subterrânea de cada biodigestor possui formato de tronco de pirâmide invertida, tendo a base menor (fundo do biodigestor) dimensões de $27 \times 12$ m, a base maior (superior) dimensões de 32 x 17 m e profundidade de 2,5 m, perfazendo volume de 1.073,19 $\mathrm{m}^{3}$, sendo cobertos com geomembranas flexíveis (gasômetros) de policloreto de vinila (PVC), que apresentam 1,0 mm $(1.000 \mu \mathrm{m})$ de espessura.

Figura 3. Biodigestores Modelo Canadense

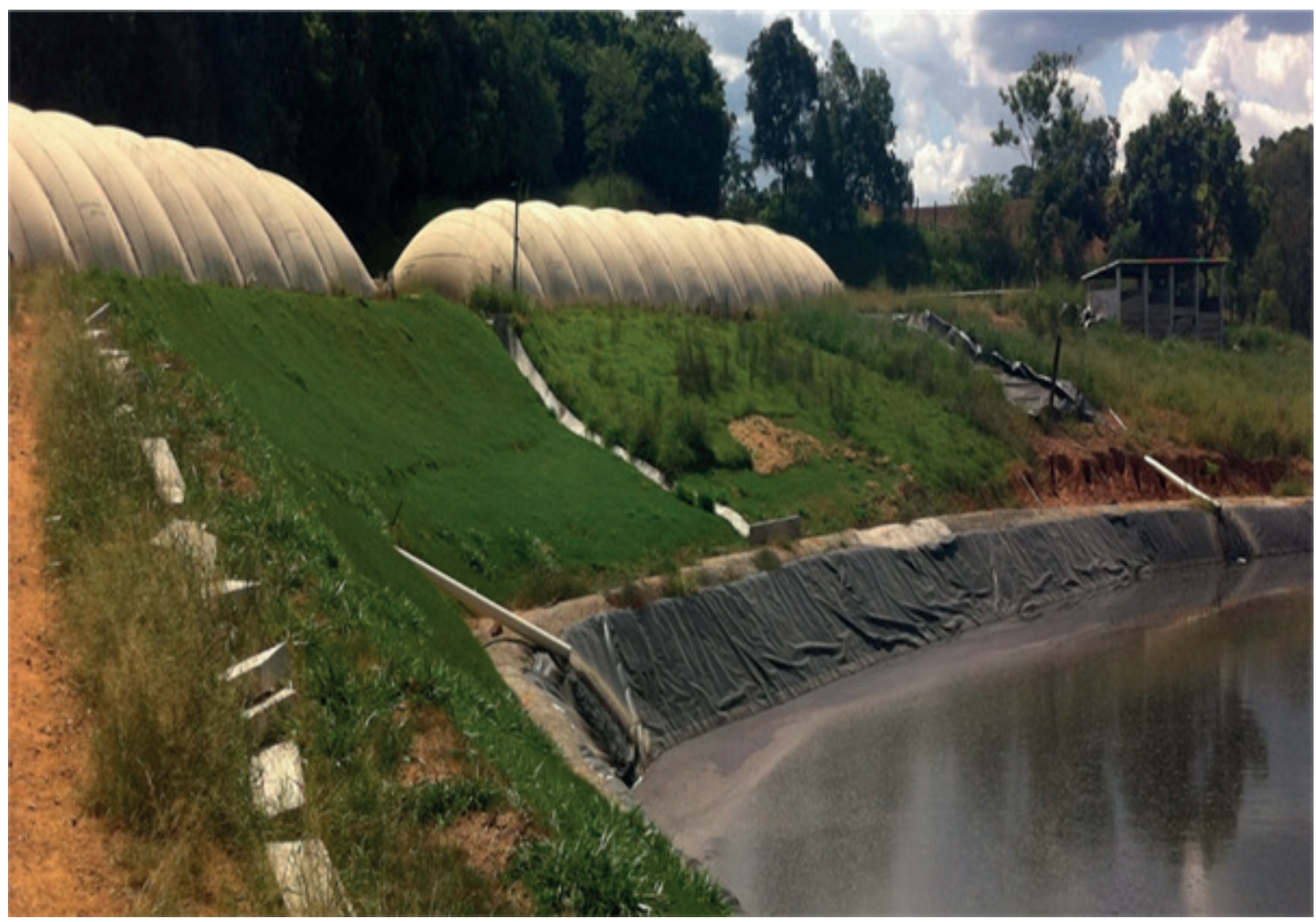

Fonte: Veloso (2014).

Após um tempo de retenção hidráulica $(\mathrm{TRH})$ de 30 dias nos biodigestores, os resíduos são escoados, por gravidade, por meio de tubos de policloreto de vinila (PVC) de $200 \mathrm{~mm}$ para uma lagoa de estabilização ("H”, FIGURA 1 e FIGURA 4), que tem o formato elíptico, apresentando eixo maior de $60 \mathrm{~m}$, eixo menor de $31 \mathrm{~m}$, profundidade de 3,5 m e volume de 20.451,82 $\mathrm{m}^{3}$. 
Figura 4. Lagoa de Estabilização

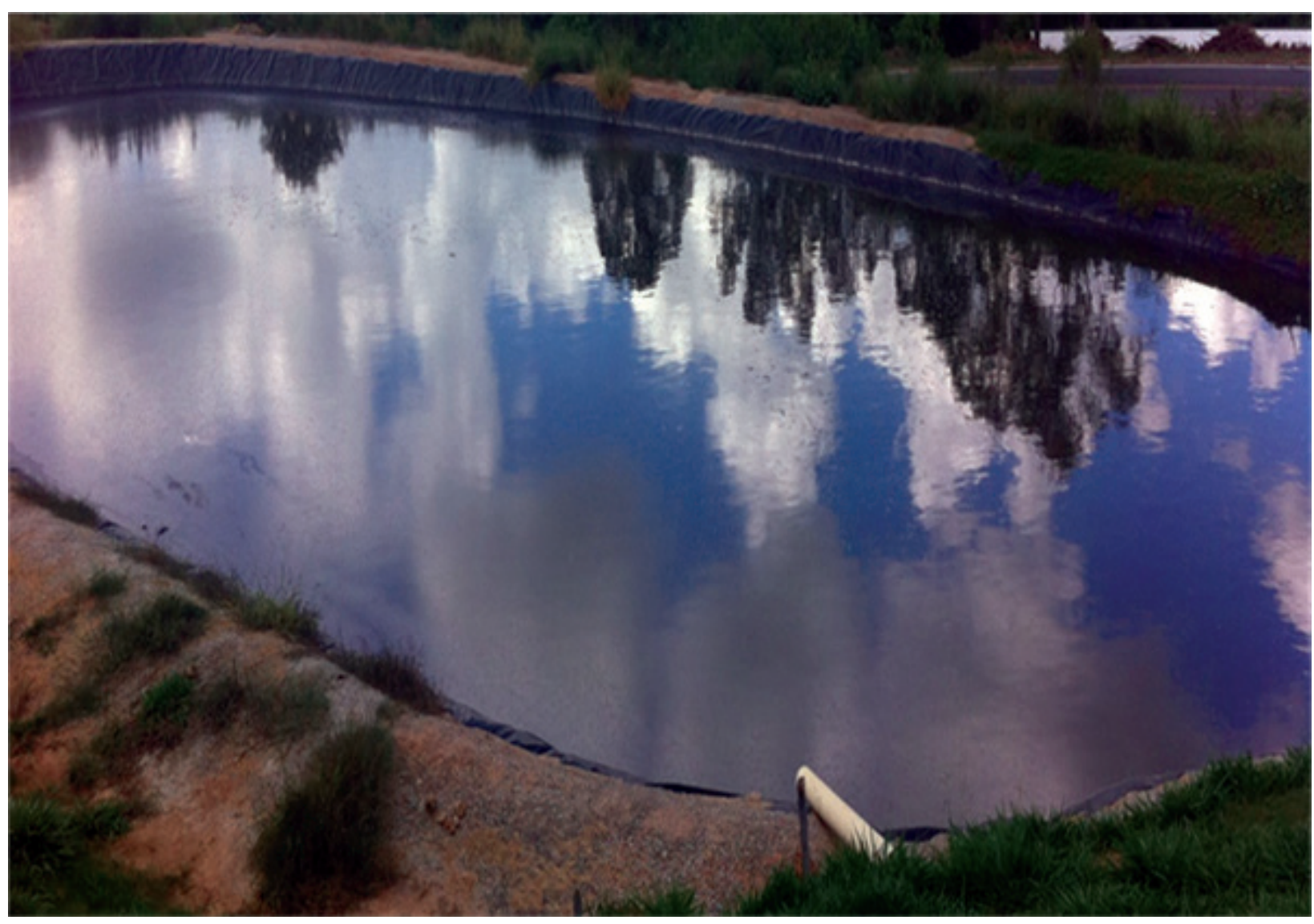

Fonte: Veloso (2014).

As paredes laterais e os fundos do tanque de equalização, dos biodigestores e da lagoa de estabilização são revestidos com lona de impermeabilização de policloreto de vinila (PVC), que possui $0,8 \mathrm{~mm}(800 \mu \mathrm{m})$ de espessura.

A planta de geração de eletricidade ("I", FIGURA 1 e FIGURA 2) é constituída pelo motor de combustão interna (máquina primária), que é responsável por gerar a energia mecânica e pelo gerador síncrono, que transforma a energia mecânica proveniente do motor em energia elétrica. 
Figura 5. Conjunto motor gerador de eletricidade. Observação: $A=$ motor Mercedez Benz; $B=$ gerador de eletricidade; $C=$ sistema de purificação do biogás; $D=$ painel de controle.

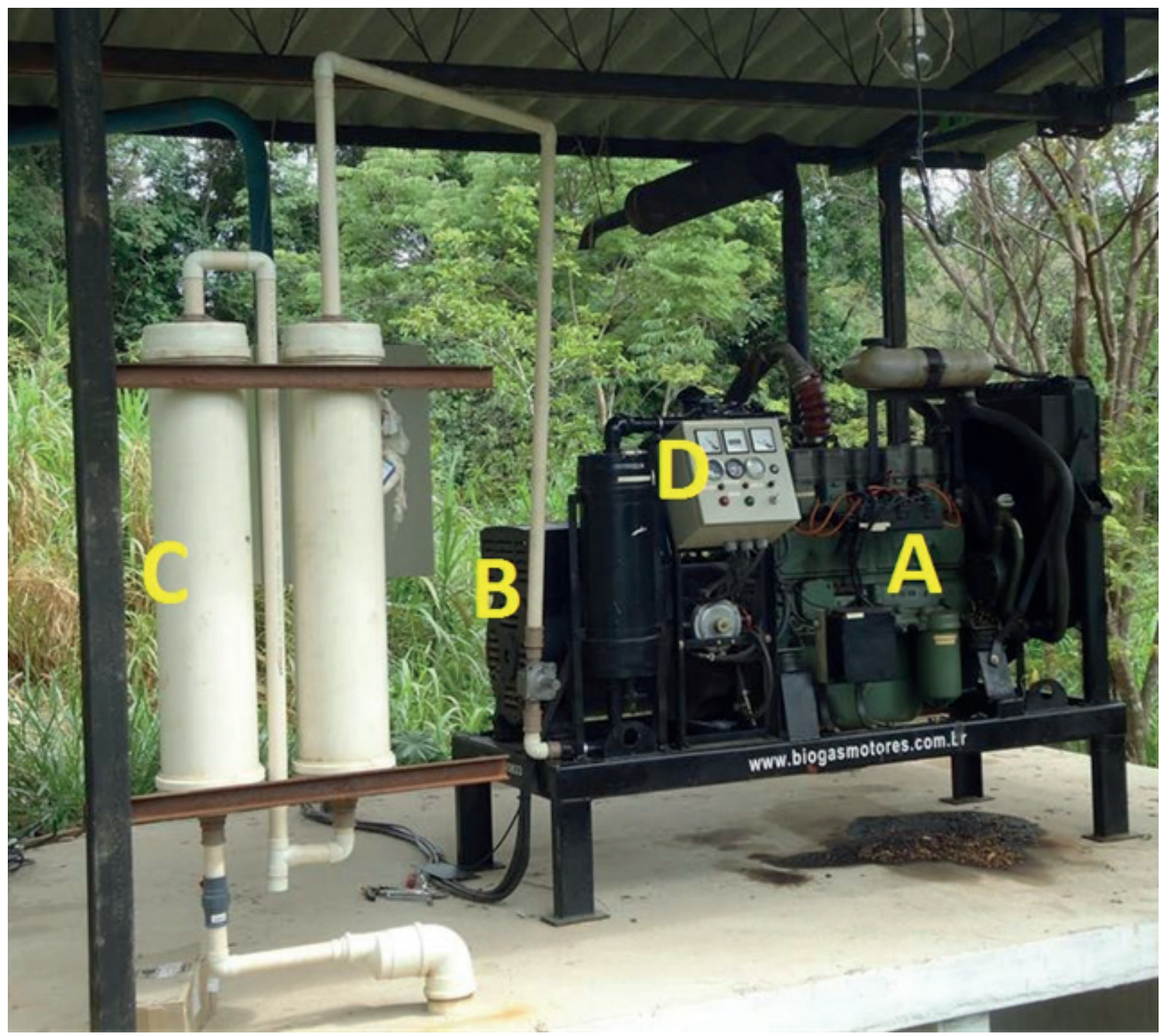

Fonte: Veloso (2014).

O biogás é conduzido do biodigestor até o conjunto motor gerador por tubulação de policloreto de vinila (PVC), que contém pontos de purga d'água, para remoção de umidade, que se desenvolve na biodigestão anaeróbia. Além disso, com o objetivo de se evitar o efeito corrosivo do gás sulfídrico ou sulfeto de hidrogênio $\left(\mathrm{H}_{2} \mathrm{~S}\right)$, são utilizados filtros de limalha de ferro para a purificação do biogás ("C" da Figura 2), pois conforme descreveram Souza et al. (2008) e Martins e Oliveira (2011), esse gás ocasiona danos à conversão de energia, bem como a corrosão dos componentes do sistema.

O motor do conjunto gerador é de combustão interna, marca Mercedes Benz ${ }^{\circledR}$, modelo 352 (motor diesel adaptado a Otto), para o uso do biogás como combustível, o qual, de acordo com o fabricante, apresenta potência variando de 92 a 141 kW e um consumo aproximado de $49,10 \mathrm{~m}^{3} \mathrm{~h}^{-1}$ ("A" da Figura 2). 
O gerador de eletricidade é trifásico da marca WEG ("B" da Figura 2), modelo GTA 201 Al HE, 220/380 VCA (Volts em Corrente Alternada), 3.600 rpm, 60 Hz, com capacidade nominal de geração de 125 kVA (100 kW). Para cálculos de geração de energia elétrica em baixa tensão, considerando-se um fator de potência de 0,8 (cos $\varnothing)$, esse gerador apresenta potência eficaz de 100 kVA (80 kW) (CERVI et al., 2010).

O período de funcionamento do conjunto motor gerador é de 24 horas por dia.

\section{Análise quantitativa da produção de biogás}

A quantidade de biogás produzida nos biodigestores foi determinada pela demanda do conjunto motor gerador, analogamente ao que foi descrito por Martins e Oliveira (2011) e Cervi et al. (2010).

\section{Análise qualitativa da produção de biogás}

Utilizou-se do kit portátil para análise da concentração de gases em biogás (KUNZ; SULZBA$\mathrm{CH}, 2007)$, o qual permite a análise de gás sulfídrico $\left(\mathrm{H}_{2} \mathrm{~S}\right)$, amônia $\left(\mathrm{NH}_{3}\right)$, gás carbônico $\left(\mathrm{CO}_{2}\right)$ e metano $\left(\mathrm{CH}_{4}\right)$.

O kit portátil possibilita que por meio de um método analítico colorimétrico ou volumétrico um volume específico de biogás entre em contato com determinados reagentes. Desta forma, é possível fazer a análise colorimétrica das concentrações de gás sulfídrico e amônia presentes no biogás, sendo que as concentrações de gás carbônico são obtidas por método volumétrico, e a concentração de metano obtida por diferença (mas, primeiramente, seguindo-se as especificações do manual de análise do kit, determinaram-se as concentrações de $\mathrm{CO}_{2}$ ).

Além do manual de análise, o kit portátil é composto por: tabela colorimétrica para determinação da concentração de gases; reagentes para realização das análises; seringas amostradoras; frascos para reação química e comparação de cor; saco amostrador para coleta da amostra de biogás, que será utilizado para todas as análises; conjunto de seringas para determinação de metano por meio do método volumétrico.

No período de janeiro a março de 2016, foram realizadas 10 amostragens de biogás, sendo que os dados resultantes dessas amostragens foram tabulados e submetidos em planilhas do aplicativo Excel obtendo-se, assim, os valores médios para a concentração de $\mathrm{H}_{2} \mathrm{~S}, \mathrm{NH}_{3}, \mathrm{CO}_{2}$ e $\mathrm{CH}_{4}$.

\section{Resultados e discussão}

A estimativa da produção diária de biogás foi de 1.178,40 $\mathrm{m}^{3}$. Na propriedade estudada, essa totalidade é consumida pelo grupo motor gerador, que converte a energia química do biogás em eletricidade, atendendo a toda demanda energética da unidade de produção, incluindo uma residência.

Como a suinocultura é uma atividade sujeita à volatilidade do mercado, a produção de biogás representa uma opção de economia para o setor produtivo, visto que a sua energia química pode ser convertida em energia térmica e/ou elétrica, as quais podem ser utilizadas para o abastecimento das unidades de produção (MARTINS; OLIVEIRA, 2011).

Com a produção descentralizada de energia elétrica pela propriedade rural, haverá menor dependência da energia proveniente da concessionária local, sendo também possível a comercialização do excesso de eletricidade. Contudo, um fator limitante da viabilidade técnica do sistema de geração de eletricidade é o número de animais na unidade de produção, que não deve ser inferior a 500 unidades, além de outros fatores que envolvem, por exemplo, a demanda de energia de instalações e 
equipamentos, a capacidade de investimento do produtor e o domínio técnico do sistema de geração (MARTINS; OLIVEIRA, 2011).

Um ponto importante a ser considerado é que a energia elétrica encontra-se em destaque em todos os setores da economia mundial, além de ser um importante insumo básico para o desenvolvimento do Brasil, que tem na hidroeletricidade sua principal fonte energética. Entretanto, é com frequência que empreendimentos hidrelétricos têm se revelado insustentáveis no Brasil e no mundo, em virtude dos inúmeros problemas ambientais e sociais (CRUZ; SILVA, 2010).

Desta forma, considerando o crescente interesse pelo aproveitamento energético dos resíduos oriundos da biomassa (AVACI et al., 2013; XAVIER; LUCAS JÚNIOR, 2010; CONVERTI et al., 2009), a possibilidade de criação de fontes de energia descentralizadas e em pequena escala é fundamental para o desenvolvimento sustentável. Assim, unidades que utilizam fontes renováveis e não demandam alta tecnologia para instalação e/ou mão de obra especializada para sua execução são soluções para produtores rurais, que podem diminuir sua dependência de energia das concessionárias de eletricidade (CERVI et al., 2010).

Esperancini et al. (2007) demonstram que estudos nessa área podem servir de base para o desenvolvimento de políticas públicas direcionadas ao aproveitamento de biomassa para a produção de energia a baixo custo.

Considerando as concentrações de amônia presentes no biogás, em três das 10 amostragens realizadas, os valores encontrados foram iguais a zero; em uma amostragem, o valor obtido foi igual a 15 ppmV (partes por milhão por volume) e em seis amostragens os valores obtidos foram de 175 ppmV.

No que se refere às concentrações de gás sulfídrico, o número de amostragens realizadas também foram 10 e, em nove observações, foram encontradas as concentrações de 610 ppmV. Por sua vez, em apenas uma das análises foi encontrada a concentração de 460 ppmV.

Em relação à concentração de metano, o valor médio encontrado foi de $68,42 \%$, enquanto o valor médio observado para a concentração de gás carbônico foi de 31,58\%.

Diante disso, é importante destacar que o biogás produzido nos biodigestores por meio da biodigestão anaeróbia consiste de uma mistura de metano, dióxido de carbono, traços de vapor de água, sulfeto de hidrogênio, nitrogênio, oxigênio, hidrogênio, monóxido de carbono, amônia, mercaptanas, entre outros (GALBIATTI et al., 2010; PRADO et al., 2010; PRADO; CAMPOS, 2008).

De acordo com Lansing et al. (2008), a composição do biogás obtida nos biodigestores é: 50 a $70 \%$ de metano, 30 a $40 \%$ de dióxido de carbono, 1,0 \% de hidrogênio, 0,5 \% de nitrogênio, 0,1 \% de monóxido de carbono, 0,1 \% de oxigênio e 0,1 \% de sulfeto de hidrogênio.

Em se tratando da produção de energia renovável, o metano é o combustível por excelência, e o biogás é tanto mais puro e mais energético quanto maior o teor de metano (PRADO; CAMPOS, 2008; CHERNICHARO, 1997).

Portanto, se a conversão da energia química do biogás em energia térmica ou elétrica é pretendida, deve-se prever um custo adicional para purificação do biogás (CHERNICHARO, 1997), uma vez que teores de gás sulfídrico variando de 300 a 500 partes por milhão (ppm) podem ocasionar danos à conversão de energia (HOLM-NIELSEN et al., 2009). 


\title{
Conclusão
}

A conversão da energia química do biogás em eletricidade, ou seja, os 1.178,40 $\mathrm{m}^{3}$ de biogás produzidos diariamente na unidade de produção são convertidos em energia elétrica, que atende a toda demanda do local de $13.780 \mathrm{~kW}$ por mês.

Essa conversão de energia só é possível pela porcentagem de metano, que é o combustível renovável por excelência. No presente trabalho o valor dessa porcentagem foi de $68,42 \%$, que está acima do recomendado pela literatura pertinente que é de $65 \%$.

Em tempos de busca pela sustentabilidade ambiental, o processo de biodigestão anaeróbia pela implementação de biodigestores representa uma opção para o manejo e tratamento da biomassa residual da atividade suinícola.

\section{Sustainable assessment of biogas in a swine production unit and its reuse of energy}

\begin{abstract}
This study aimed to analyze quantitative and qualitatively the biogas from a swine production unit, reporting the energy reuse. The amount of biogas produced in the biodigesters was determined by the generator set demand. In regarding to the biogas qualitative analysis, a portable kit was used to analyze the concentration of gases in biogas; this portable kit allows the analysis of sulfuric gas $\left(\mathrm{H}_{2} \mathrm{~S}\right)$, ammonia $\left(\mathrm{NH}_{3}\right)$, carbon dioxide $\left(\mathrm{CO}_{2}\right)$ and methane $\left(\mathrm{CH}_{4}\right)$. The results obtained present an estimated daily production of biogas of $1.178,40 \mathrm{~m}^{3}$. Considering the concentrations of ammonia in the biogas, the results indicate the values found were equal to zero in three of the 10 samplings, in one sample the value obtained was $15 \mathrm{ppmV}$ (parts per million by volume), and in six samples the values obtained were $175 \mathrm{ppmV}$. For sulfuric gas concentrations, ten samplings were also carried out. For nine samplings, the concentration found was $610 \mathrm{ppmV}$, and for one sampling the concentration found was $460 \mathrm{ppmV}$. In times of adaptation to environmental legislation and for sustainability reasons, the process of anaerobic biodigestion represents an option for the management and treatment of swine residual biomass, positively impacting the rural area.
\end{abstract}

Keywords: Constructions. Swine waste. Renewable energy. Swine breeding. Sustainability.

\section{Referências}

ANGONESE, A. R.; CAMPOS, A. T.; WELTER, R. A. Potencial de redução de emissão de equivalente de carbono de uma unidade suinícola com biodigestor. Engenharia Agrícola, Jaboticabal, v. 27, n. 3, p. 648-657, set./dez. 2007. Disponível em: <http://www.scielo.br/pdf/eagri/v27n3/a07v27n3. pdf >. Acesso em: 08 ago. 2016.

AVACI A. B.; SOUZA S. N. M.; CHAVES L. I.; NOGUEIRA C. E. C.; NIEDZIALKOSKI R. K.; SECCO D. Avaliação econômico-financeira da microgeração de energia elétrica proveniente de biogás da suinocultura. Revista Brasileira de Engenharia Agrícola e Ambiental, Campina Grande, v. 17, n. 4, p. 456-452, 2013. Disponível em: <http://www.scielo.br/pdf/rbeaa/v17n4/a15v17n4.pdf>. Acesso em: 05 ago. 2016. 
CERVI, R. G.; ESPERANCINI, M. S. T.; BUENO, O. C. Viabilidade econômica da utilização do biogás produzido em granja suinícola para geração de energia elétrica. Engenharia Agrícola, Jaboticabal, v. 30, n. 5, p. 831-844, set./out. 2010. Disponível em: <http://www.scielo.br/pdf/eagri/v30n5/ v30n5a06.pdf>. Acesso em: 25 set. 2016.

CHERNICHARO, C. A. L. Reatores anaeróbios. Belo Horizonte: UFMG: DESA, 1997. $246 p$.

CONVERTI, A.; OLIVEIRA, R. P. S.; TORRES, B. R.; LODI, A.; ZILLI, M. Biogas production and valorization by means of a two-step biological process. Bioresource Technology, Oxford, v. 100, n. 23, p. 5771-5776, 2009.

COSTA, Z. F.; BUENO, O. C. Análise das eficiências energética e econômica da produção de leite bovino em explorações familiares na região de Botucatu, estado de São Paulo. Revista de Economia Agrícola, São Paulo, v. 57, n. 2, p. 37-48, abr./maio/jun. 2010. Disponível em: <http://www.iea. sp.gov.br/ftpiea/publicacoes/rea/2010/rea2-3-2010.pdf>. Acesso em: 11 jun. 2016.

CRUZ, C. B.; SILVA, V. P. Grandes projetos de investimento: a construção de hidrelétricas e a criação de novos territórios. Sociedade \& Natureza, Uberlândia, v. 22, n. 1, 2010. Disponível em: <http:// www.scielo.br/pdf/sn/v22n1/13.pdf>. Acesso em: 11 jun. 2016.

ESPERANCINI, M. S. T.; COLEN F.; BUENO O. C.; PIMENTEL A. E. B.; SIMON E. J. Viabilidade técnica e econômica da substituição de fontes convencionais de energia por biogás em assentamento rural do estado de São Paulo. Engenharia Agrícola, Jaboticabal, v. 27, n. 1, p. 110-118, jan./abr. 2007. Disponível em: <http://www.scielo.br/pdf/eagri/v27n1/04.pdf>. Acesso em: 02 abr. 2016.

GARCIA, M. A. Ecologia aplicada a agroecossistemas como base para a sustentabilidade. Informe Agropecuário, Belo Horizonte, v. 22, n. 213, p. 30-38, nov./dez. 2001.

GAlBIATTI, J. A.; CARAMElO, A. D.; SILVA, F. G.; GERARDI, E. A. B.; CHICONATO, D. A. Estudo qualiquantitativo do biogás produzido por substratos em biodigestores tipo batelada. Revista Brasileira de Engenharia Agrícola e Ambiental, Campina Grande, v. 14, n. 4, p. 432-437, 2010. Disponível em: <http://www.scielo.br/pdf/rbeaa/v14n4/v14n04a13.pdf>. Acesso em: 30 jul. 2016.

HOLM-NIELSEN, J. B.; AL SEADI, T.; OLESKOWICZ-POPIEL, P. The future of anaerobic digestion and biogas utilization. Bioresource Technology, Oxford, v. 100, n. 22, p. 5478-5484, 2009.

KUNZ, A.; SULZBACH, A. Kit biogas portátil. Concórdia: EMBRAPA - CNPSA, 2007. 2p. Disponível em: <https://www.embrapa.br/suinos-e-aves/busca-de-publicacoes/-/publicacao/439433/kit-biogas-portatil-para-analise-de-concentracao-de-gas-metano-amonia-e-gas-sulfidrico-em-biogas $>$. Acesso em: 25 jan. 2017.

LANSING, S.; BOTERO, R. B.; MARTIN, J. F. Waste treatment and biogas quality in small-scale agricultural digesters. Bioresource Technology, Oxford, v. 99, n. 13, p. 5881-5890, 2008.

MARTINS, F. M.; OLIVEIRA, P. A. V. Análise econômica da geração de energia elétrica a partir do biogás na suinocultura. Engenharia Agrícola, Jaboticabal, v. 31, n. 3, p. 477-486, maio/jun. 2011. Disponível em: <http://www.scielo.br/pdf/eagri/v31n3/a08v31n3.pdf>. Acesso em: 25 fev. 2016. 
ODUM, H. T. Environmental Accounting: emergy and decision making. New York, John Wiley, 1995. 384p.

ORRICO JÚNIOR, M. A. P.; ORRICO, A. C. A.; LUCAS JÚNIOR, J. Produção animal e o meio ambiente: uma comparação entre potencial de emissão de metano dos dejetos e a quantidade de alimento produzido. Engenharia Agrícola, Jaboticabal, v. 31, n. 2, p. 399-410, mar./abr. 2011. Disponível em: <http://www.scielo.br/pdf/eagri/v31n2/a20v31n2.pdf>. Acesso em: 25 jan. 2016.

PRADO, M. A. C.; CAMPOS, C. M. M. Produção de biogás no tratamento dos efluentes líquidos do processamento de Coffea arabica $L$. em reator anaeróbico UASB para o potencial aproveitamento na secagem do café. Ciência e Agrotecnologia, Lavras, v. 32, n. 3, p. 938-947, maio/jun. 2008. Disponível em: <http://www.scielo.br/pdf/cagro/v32n3/a35v32n3.pdf>. Acesso em: 22 jan. 2016.

PRADO, M. A. C.; CAMPOS, C. M. M.; SILVA, J. F. Estudo da variação da concentração de metano no biogás produzido a partir de águas residuárias do café. Ciência e Agrotecnologia, Lavras, v. 34, n. 2, p. 475-484, mar./abr. 2010. Disponível em: <http://www.scielo.br/pdf/cagro/v34n2/29.pdf>. Acesso em: 22 jan. 2016.

SANTOS, R. R.; SIMON, E. J. Análise energética do milho em sistema de plantio direto, no assentamento rural da Fazenda Pirituba, Itaberá/SP. Revista Energia na Agricultura, Botucatu, v. 25, n. 1, p. 121-137, jan./fev./mar. 2010. Disponível em: <http://revistas.fca.unesp.br/index.php/energia/ article/view/49/31 > . Acesso em: 27 mar. 2016.

SOUZA, C. F.; CAMPOS, J. A.; SANTOS, C. R. et al. Produção volumétrica de metano - dejetos de suínos. Ciência e Agrotecnologia, Lavras, v. 32, n. 1, p. 219-224, 2008. Disponível em: < http:// www.scielo.br/pdf/cagro/v32n1/a32v32n1.pdf>. Acesso em: 14 jan. 2016.

VElOSO, A. V.; CAMPOS, A. T.; PAULA, V. R.; DOURADO, D. C.; YANAGI JÚNIOR, T.; SILVA, E. B. Energetic efficiency of a production system in swine deep bed. Engenharia Agrícola, Jaboticabal, $v$. 32, n. 6, p. 1068-1079, nov./dez. 2012. Disponível em: <http://www.scielo.br/pdf/eagri/v32n6/08. pdf $>$. Acesso em: 13 jan. 2016.

VELOSO, A. V. Análise ambiental e energética de sistema de produção de suínos com tratamento de dejetos em biodigestor. 2014. 193 p. Tese (Doutorado em Engenharia Agrícola) - Universidade Federal de Lavras, Lavras, 2014.

XAVIER C. A. N.; LUCAS JÚNIOR J. Parâmetros de dimensionamento para biodigestores batelada operados com dejetos de vacas leiteiras com e sem uso de inóculo. Engenharia Agrícola, Jaboticabal, v. 30, n. 2, p. 212-223, mar./abr. 2010. Disponível em: <http://www. scielo.br/pdf/eagri/v30n2/v30n2a03.pdf>. Acesso em: 10 jul. 2016.

Submetido em: 04/08/2017.

Aceito em: 22/11/2017. 
Como citar:

ABNT

MARIN, D. B.; VELOSO, A. V.; MATTIOLO, M.C.; SOARES, J. F. Formas e estádios de aplicação de adubação nitrogenada no desenvolvimento e produtividade da soja. Revista Agrogeoambiental, Pouso Alegre, v. 10, n. 4, p. 113-126, abr./jun. Doi: http://dx.doi.org/10.18406/2316-1817v10n420181247

APA

MARIN, D. B., VELOSO, A. V., MATTIOLO, M.C. \& SOARES, J. F. (2018). Formas e estádios de aplicação de adubação nitrogenada no desenvolvimento e produtividade da soja. Revista Agrogeoambiental, 10 (4), 113-126.

Doi: http://dx.doi.org/10.18406/2316-1817v10n420181247

ISO

MARIN, D. B.; VELOSO, A. V.; MATTIOLO, M.C. e SOARES, J. F Formas e estádios de aplicação de adubação nitrogenada no desenvolvimento e produtividade da soja. Revista Agrogeoambiental, 2018, vol. 10, n. 4, pp. 113-126. Eissn 2316-1817. Doi: http://dx.doi.org/10.18406/2316-1817v10n420181247

VANCOUVER

Marin DB, Veloso AV, Mattioli MC, Soares JF. Formas e estádios de aplicação de adubação nitrogenada no desenvolvimento e produtividade da soja. Rev agrogeoambiental. 2018 abr./jun.; 10(4): 113-126. Doi: http://dx.doi.org/10.18406/2316-1817v10n420181247 